\title{
Nanostructured interfaces for enhancing mechanical properties of composites: Computational micromechanical studies
}

\author{
Mishnaevsky, Leon
}

Published in:

Composites Part B: Engineering

Link to article, DOI:

10.1016/j.compositesb.2014.08.029

Publication date:

2015

Document Version

Peer reviewed version

Link back to DTU Orbit

Citation (APA):

Mishnaevsky, L. (2015). Nanostructured interfaces for enhancing mechanical properties of composites:

Computational micromechanical studies. Composites Part B: Engineering, 68, 75-84.

https://doi.org/10.1016/j.compositesb.2014.08.029

\section{General rights}

Copyright and moral rights for the publications made accessible in the public portal are retained by the authors and/or other copyright owners and it is a condition of accessing publications that users recognise and abide by the legal requirements associated with these rights.

- Users may download and print one copy of any publication from the public portal for the purpose of private study or research.

- You may not further distribute the material or use it for any profit-making activity or commercial gain

- You may freely distribute the URL identifying the publication in the public portal

If you believe that this document breaches copyright please contact us providing details, and we will remove access to the work immediately and investigate your claim 


\title{
NANOSTRUCTURED INTERFACES FOR ENHANCING MECHANICAL PROPERTIES OF COMPOSITES: Review of computational micromechanical studies
}

\author{
Leon MISHNAEVSKY Jr. \\ Department of Wind Energy, Technical University of Denmark, \\ Ris $\emptyset$ Campus, Frederiksborgvej 399, Roskilde, 4000 Denmark \\ Email: lemi@dtu.dk.
}

\begin{abstract}
:
Computational micromechanical studies of the effect of nanostructuring and nanoengineering of interfaces, phase and grain boundaries of materials on the mechanical properties and strength of materials and the potential of interface nanostructuring to enhance the materials properties are reviewed. Several groups of materials (composites, nanocomposites, nanocrystalline metals, wood) are considered with view on the effect of nanostructured interfaces on their properties,. The structures of various nanostructured interfaces (protein structures and mineral bridges in biopolymers in nacre and microfibrils in wood; pores, interphases and nanoparticles in fiber/matrix interfaces of polymer fiber reinforced composites and nanocomposites; dislocations and precipitates in grain boundaries of nanocrystalline metals) and the methods of their modeling are discussed. It is concluded that nanostructuring of interfaces and phase boundaries is a powerful tool for controlling the material deformation and strength behavior, and allows to enhance the mechanical properties and strength of the materials. Heterogeneous interfaces, with low stiffness leading to the localization of deformation, and nanoreinforcements oriented normally to the main reinforcing elements can ensure the highest toughness of materials.
\end{abstract}

Keywords: B: Interface/interphase, C: Computational modelling, C: Micro-mechanics, B: Damage tolerance

\section{Introduction}

Mechanical properties and strength of materials can be enhanced by modifying the structures of the materials at micro- and nanoscales. Various strategies and techniques of the structure modification have been developed to ensure the better service properties of materials [1]. One of the promising directions of the materials modification for the properties enhancement is based on the control and modification of interface properties [2-11]. Interfaces, phase and grain boundaries represent often relatively instable and deformable regions of materials. The typical deformation and degradation scenario of materials includes the formation and development of highly deformed regions (e.g., shear bands), defects, cracks in the deformable regions. One of the ways to control the deformation scenario is to modify the structure of the less stable, deformable elements of the material at the lower scale level, thus, influencing the deformation development and damage initiation processes. The introduction of geometrical structural 
inhomogeneities into instable phases, like defects, nanoscale reinforcements, structural gradients, can make it possible to control the local stress concentration, localization of deformation in weaker phases and thus microstructure evolution and microstructural adaptation of the material. Toughening the weak regions, interfaces or other defects (which otherwise serve as sites of damage initiation) channels the deformation energy into the lower scale level. Thus, nanomodification of weak regions and structural defects can be used to influence the damage evolution and improve the damage resistance of the material.

In this paper, we provide a short overview of the computational micromechanical studies of the effect of nanostructuring and nanoengineering of interfaces, phase and grain boundaries of materials on the mechanical properties and strength of materials. We consider several groups of materials (composites, nanocomposites, nanocrystalline metals, wood) and explore (using numerical experiments) how the interface structures influences the properties of the materials. Considering wood (multilayered nanoreinforced cellular material), fiber reinforced polymer composites, nanocomposites and hybrid composites, as well as ultrafine grained metals, we demonstrate that the availability of special structures in grain boundaries/phase boundaries/interfaces represents an important and promising source of the enhancement of the materials strength. Since the structures formed in the interfaces/phase boundaries are at the lower scale level than adjoining structural elements (fibers, grains, etc), we will use the term "nanostructuring of interfaces" here (although in some cases, the considered materials like "ultrafine grained titanium" represent nanostructured materials itself).

\section{Biological materials: Role of structured interfaces}

Natural biological materials demonstrate often extraordinary strength, damage resistance and toughness. They are often stronger and tougher, than could be assumed from averaging their component properties. So, nacre, which consists by $95 \%$ of $\mathrm{CaCO}_{3}$, has a work of fracture that is 3,000 times higher than that of the monolithic $\mathrm{CaCO}_{3}$ [12]. Typically, strong biological materials (bones, sea shells, insect cuticles) represent composites, consisting of hard (mineral) and soft (biopolymer) phases, organized in complex multilevel structures [13, 14].

\subsection{Role of structured interfaces in rigid biological materials: Nacre and teeth}

The important role of interfaces for the strength and toughness of biological materials has been demonstrated in many works. Mayer and Sarikaya [15] reviewed the structures and properties of rigid biological composites, and noted that biointerfaces are seldom sharp, and typically have very complex structure. Interfaces can be interpenetrating and form the wide transitional zone, or change from columnar calcitic structure to aragonite nacreous structure (in the shell of red abalone). The broad, structured interfaces with interpenetrating, gradient nanostructures increase the toughness of the biomaterials.

For instance, nacre of mollusks contains $95 \%$ of aragonite platelets and only $5 \%$ of biopolymer. Thin layers of biopolymer between the platelets can be considered as interfaces in this material [16]. The biopolymer layers have in fact a very complex structure: they represent organic macromolecules, containing polysacharides and protein fibers. Furthermore, the biopolymer 
thin layers of nacre contain nanopores and also inorganic mineral bridges, linking the aragonite platelets [16-19], see Figure 1. The adhesive fibers elongate in a stepwise manner, when nacre is loaded, as folded domains or loops are pulled open. Sawtooth pattern of the force-extension curve in the protein is a result of the successive domain unfolding. During the crack propagation, the energy is absorbed by the interface debonding and by the shearing of the protein layer.

Katti et al. [20] simulated the effect of nanoasperities in the platelets/biopolymer interfaces of nacre on the mechanical properties. While only marginal effect of nanoasperites on the mechanical properties was proved in the simulations, the authors noted that the positive role of nanoasperities can include the effects of larger surface area of minerals and confinement of polymer. Qi et al. [21] modeled the mechanical behavior of nacre numerically, taking into account the unfolding of protein molecules in the organic matrix. The nonlinear stress-strain behavior was observed, with an apparent "yield" stress (related with the unfolding events in the organic layers and to the mitigation of load transfer to the aragonite tablets) and hardening (related with the shear in the organic layers).

Song and Bai [16] evaluated the fracture toughness in the "brick bridge mortar" structure of nacre and showed that the availability of nanostructures in the nacre interfaces (i.e., mineral bridges between aragonite platelets located in the bioolymer layers) is one of the reasons for the high toughness of nacre. The mineral bridges reinforce the weak interface, and control the crack propagation in the interfaces (biopolymer layers).

Another prominent example of nanostructured biointerfaces is the multilevel interfaces of dental-enamel junction in teeth [22]. The dental -enamel junction (DEJ) has so-called three level scalopped structure (convexities directed toward dentin, and concavities directed toward enamel) and graded variation of properties. It is extremely fracture resistant; the crack initiation stress in DEJ is rather high, and cracks dont cross DEJ, but tend to deflect.

Thus, nanostructuring of interfaces and thin biopolymer layers between mineral platelets play an important role for the strength and toughness of biocomposites, and represent one of the sources of high strength and toughness of these materials.

\subsection{Wood as a cellular material with multiple heterogeneous layers}

Wood is a natural composite with very high strength/weight ratio [23]. The structure of softwood is usually described at four different structural levels (see Figure). At the macroscale, it is the annual rings (alternated light and dark rings, called earlywood and latewood respectively; the earlywood is characterized by cells with larger diameters and thinner cell walls than in latewood). At the mesoscale, it is a cellular material, built up by hexagon-shapedtube cells oriented fairly parallel to the stem direction. At the microscale, cell walls of wood consists of 4 layers with different microstructures and properties, which are called usually $\mathrm{P}$, $\mathrm{S} 1, \mathrm{~S} 2$ and S3, and middle layer $\mathrm{M}$ acts as bonding material. At the nanoscale, the layers in the secondary wall of a tracheid cell are built of several hundred individual lamellae with varied volume fractions and characteristic microfibril angles (MFAs). The layers, building the hexagon cells, can be considered as one voluminous element (the thick layer S2) and several almost two-dimensional layers, M, P, S1, S3. The thickness of the S2 layer is $10 \ldots 100$ times higher than that of other layers.

The mechanical behavior and strength of wood are determined by the complex interaction between all the elements at different scales. In order to analyze the effect of nanostructures 
(angle and distribution of microfibrils in each layer) on the mechanical properties of the wood, Qing and Mishnaevsky Jr. [24, 25] developed and employed 3D multiscale computational model of wood as layered fibril reinforced cellular material. In the numerical experiments, the authors demonstrated that the variation of microfibril angles represents a rather efficient mechanism of the control of stiffness of wood. By increasing the MFAs (microfibril angle, i.e., the angle between microfibrils and horizontal line), the drastic increase of shear stiffness in 1-2 direction is achieved, without any sizable losses of the transverse Young modulus and shear modulus in the 23 plane. The thick layer S2 is responsible mainly for the stiffness and deformation behavior of wood. The nanostructures of thin layers (microfibril angles in S1, S3) have still a rather strong effect on the peak stress in earlywood under tensile loading (22\% higher peak stress when the fibril angles changes from 70 to 50 degrees in the thin S1 layer).

Still, the thin layers play different roles. The microfibrils in S1 and S3 layers are perpendicular to those in S2 layer. So, the S1 and S3 layers are responsible mainly for the resistance against buckling, collapse and fracture, and shear moduli. The layer S1 (which is much thicker in compression wood) ensuring the stability of wood under compression (S1) [26].

According to [27], the fibril distribution in thin layers (S1, S3) controls the trans- and intra-wall crack propagation, resisting the development of transwall cracks in transverse direction and preventing the intrawall cracks from becoming transwall cracks.

Thus, while the properties of wood are generally controlled by complex interplay of layered, cellular, fibrous structures at many scale levels, the variation of nanoscale structures in thin layers binding voluminous structural elements play very important roles in ensuring the optimal output properties, deformation and strength of wood.

\section{Composites and nanocomposites: Computational modeling of the effect of interfaces on the mechanical properties}

Fiber reinforced polymer composites have an excellent strength/weight ratio, and are used for various civil and mechanical engineering, energy and other applications.

Still, with view on the wind energy applications (as an example) and the growing application of off-shore extra-large wind turbines [28], which should work without repair and maintenance over decades, the further improvement of lifetime and damage resistance of the composites is required.

The strength and lifetime of fiber reinforced composites are controlled by the strength of fibers, matrix and interfaces. While the matrix is responsible for the material integrity, fibers control the stiffness of the composite in the case of glass or carbon fiber reinforced polymers. The strength of interface plays a mixed role: while the crack propagation into the fiber/matrix interface delays the matrix failure (and, thus, increases the strength of the composite), too weak interfaces lead to quick fiber pull-out and also to quick failure. So, the idea of interface based design of fiber reinforced composites was formulated (see, e.g. [3]).

\subsection{Role of interfaces in fiber reinforced composites}

In order to analyze the role of interfaces and mechanisms of composite degradation, a series of computational studies has been carried out [29-32]. A number of multifiber unit cell models were implemented in the framework of finite element method. 
In order to simulate the interface properties and interface degradation, the concept of "third material layer" was applied. Namely, since surfaces of fibers can be rather rough [33], and the interface regions in many composites contain interphases [34, 35], the interface debonding was considered not as a two-dimensional opening of two contacting plane surfaces, but rather as a three-dimensional process in a thin layer ("third material layer" between the homogeneous fiber and matrix materials[36]).

In the numerical studies, it was observed that the formation of interface cracks under tensile loading takes place often after and as a result the fiber cracking, and in the vicinity of the fiber cracks. If however the interface is weak, the interface damage begins much earlier than the fiber cracking and can be accelerated by the matrix defects. On the other side, if the interface is pre-damaged, that can lead to a slightly lower stress level in the corresponding fiber: while the stresses in the vicinity of the interface crack are rather high, the stresses in the fiber are lower than those in fibers with undamaged interfaces. The fiber cracks cause interface damage, but not vice versa. In further numerical experiments, the competition between the matrix cracking and the interface debonding was observed. In the area, where the interface is damaged, no matrix crack forms; vice versa, in the area, where the long matrix cracks is formed, the fiber cracking does not lead to the interface damage. Figure 3 shows the crack evolution in fiber reinforced polymer composites, obtained in the simulations.

Apparently, weak interfaces of composites, as such, have a negative effect of the composite properties: ultimately, the homogeneously weak interfaces will debond, and the composite will behave as a dry fiber bundle. However, the results of these studies demonstrated that local weak places in composite interfaces can be rather beneficial for the composite strength and toughness: they can prevent the matrix failure (by channeling the fracture energy into interface defects), and even delay the fiber failure. Practically, it means that a heterogeneous interface (interface with both weak and strong regions) can prevent the matrix failure, and therefore, ensure the integrity of the material. This suggests that microporous, heterogeneously predamaged interfaces in composites can be beneficial for the strength of materials [29]. The concept of porous interface which encourage the crack deflection into the interface has been discussed also by Evans, Zok and colleagues [9-11]. The porous interface was also realized in US Patent 6121169 A by Northrop Grumman Corporation.

\subsection{Nanoclay/polymer interface and region of perturbed structure around the clay: Effective interfaces model}

Moving down to the lower scale level, let us look at the effects of nanoparticles on the mechanical properties of nanocomposites.

Nanoinclusions in polymer matrix have much stronger reinforcing effect, than microscale particles. While the stiffening and strengthening of polymers by microscale particles can be roughly described by the rule-of-mixture, the addition of even very small amount of nanoparticles (of the order of few percents) can lead to the drastic improvements in modulus, strength and other properties, much above the rule-of-mixture estimations [37]. For instance, $34 \%$ higher Young's modulus and 25\% higher tensile strength were achieved in nanoclay/epoxy composite by adding only $5 \mathrm{wt} \%$ of nanoclay [38]. 38\% higher Young's 
modulus, $10.5 \%$ higher flexural strength and $25 \%$ higher microhardness of epoxy/glass fibers/nanoclay hybrid composites (HC) were achieved by adding only 5\% of nanoclay [39].

The strong, non-proportional strengthening of nanoreinforcement is related with the large interfacial area of nanoparticles, interacting with the matrix and perturbing the molecular structure of the polymer matrix (another reason is the high aspect ratio of most nanoparticles). Thus, the polymer is reinforced not only by the nanoscaled particles, but also by the layers of modified, constrained polymers surrounding each nanoparticle.

In order to simulate this effect, Odegard and his colleagues [40] proposed the effective interface model (EIM). This model allows to generalize the micromechanical models of composites onto nanocomposites. In this model, the interfacial region of nanocomposites (consisting, e.g. of perturbed polymer and interfacial molecules) is presented as a layer with properties different from those of the rest of matrix [40]. The properties of the effective interface can be determined from molecular dynamics, or inverse modeling. Since the effective interface model is not applicable for the case of high volume fraction of nanoparticles, intercalated and clustered microstructures, when the particles might touch one another, Wang, Peng and colleagues [41-43] developed a generalized effective interface model in which the effective interface layer consist of several sublayers, with different properties, and some of the outer layers can be allowed to overlap. As demonstrated in [41], elastic properties of nanoclay reinforced polymers increase proportionally to the stiffness and the fraction of the interfacial layer.

Figure 4 shows two finite element models of nanocomposites (for exfoliated and intercalated structures of nanocomposites), and (c ) Young's modulus of the polyimide/silica nanocomposite plotted versus the silica particle volume fraction for different interface properties (phenoxybenzene silica nanoparticle/polyimide system with the Young's modulus $0.3 \mathrm{GPa}$, functionalized silica nanoparticle/polyimide system with the Young's modulus 3.5GPa and a model with higher stiffness interface whose Young's modulus is $8.4 \mathrm{GPa}$; the matrix module was $4.2 \mathrm{GPa}$ ) [41, 42]. It can be seen that the interface properties strongly influence both the nanocomposite stiffness and reinforcing effect of nanoparticles.

In order to determine the elastic properties of the interphase, the inverse modeling approach was employed in [37]. According to [44], 50\% increase in the initial modulus of the polymer is observed for the $5 \%$ weight content of nanoclay. Considering the nanoclay/polymer composite with data from [44] (clay length $1000 \mathrm{~nm}$, thickness $1 \mathrm{~nm}, \mathrm{Em}=2.05 \mathrm{GPa}$, Enc=176 GPa) and varying the fraction of the intercalated nanoclay particles from zero (fully exfoliated material) to $100 \%$ (only clusters), as well as the amount of nanoparticles per cluster, one could demonstrate that for the case of fully exfoliated structure, Young's modulus of the interphase can be 2.9 times of that of polymer matrix. For the more realistic case of partially intercalated microstructure (with the fraction of $25 \%-50 \%$ of nanoparticles in clusters), the Young's modulus of the interphase becomes around $5 \ldots 8$ times that of the polymer matrix. These results are similar to the estimations by Yang and Cho [45] (from 2.44 $\mathrm{E}_{\mathrm{m}}$ and higher), Tsai, Tzeng [46] and Mesbah et al. [47] (5...8 $\left.\mathrm{E}_{\mathrm{m}}\right)$.

Thus, the layer of the polymer material with perturbed molecular structure, surrounding nanoreinforcing particles is stiffer than the rest of polymer, and represents the main reason for 
the un-proportionally strong reinforcing effect of nanoinclusions. This layer is formed as a result of interaction between large surface area of nanoinclusions and surrounding polymer chains. By modifying the nanoparticle surfaces (for instance, by oxidation of nanoreinforcement like graphene, or functionalizing the surface), one can influence the polymer-nanosurface interaction effect, and control the reinforcement degree of the nanoinclusions and mechanical properties of nanocomposites.

\subsection{Hierarchical fiber reinforced composites with nanoeingineered interfaces}

Hierarchical composites with microscale fiber reinforcement and nanoscale particles reinforcement attract a growing interest of industry and research community. It is expected that these materials (with primary microscale and secondary nanoscale reinforcements) can allow to combine the advantages of both fiber reinforced unidirectional composites and nanocomposites.

Indeed, nanostructuring of the matrix and/or fiber/matrix interfaces of fiber reinforced composites enhances the lifetime, fatigue resistance and strength of the materials in many cases. One can list a number of examples when the hierarchical design of fiber reinforced composites, with nanomodified sizings or matrix, lead to the enhancement of the material properties. For instance, $85 \%$ increase in fracture toughness was achieved introducing $4 \mathrm{phr}$ nanoclay in the matrix of carbon fiber reinforced epoxy/clay nanocomposites [48]. $0.5 \mathrm{wt} . \%$ CNT addition of carbon nanotubes (CNTs) lead to the $80 \%$ improvement of fracture toughness of carbon fiber reinforced epoxy composites [49]. 45\% increase in shear strength is achieved by adding $0.015 \mathrm{wt} \%$ nanotubes into glass fiber reinforced vinyl ester composite with [50].

Strong positive effect is achieved if the nanoreinforcing elements are placed in the fiber sizing or fiber matrix interface. So, $30 \%$ enhancement of the interlaminar shear strength was achieved by deposition of multi and single walled CNT on woven carbon fabric fibers in epoxy matrix $[51,52]$. Interlaminar toughness and strength of alumina fiber reinforced plastic laminates were improved by $76 \%$ and $9 \%$ due to the radially aligned CNTs in both interlaminar and intralaminar regions [53]. Chatzigeorgiou and colleagues [54] analyzed the effect of coating from radially aligned carbon nanotubes on carbon fibers ("fuzzy fibers") on the mechanical properties, and demonstrated that fuzzy fibers show improved transverse properties as compared with uncoated one. Even small additions of CNTs have very strong effect of these properties.

Comparing the CNT reinforcement in polymer resine and CNTS grown/deposited on the surface of different fibers [55-58], one can see that the shear strength of the composites with CNTs in resin increases typically in the range $7 \ldots 45 \%$. At the same time, the increase of the interfacial shear strength due to the CNTs grown/deposited on fibers is between $30 \%$ and $150 \%$ (and for carbon fibers even 475\%).

For the computational analysis of the effect of nanostructuring in matrix and in the fiber/matrix interface on the mechanical properties of the composites, a 3D multiscale finite element model based on the macro-micro multiple-step modeling strategy was developed [59]. Here, the glass fiber/epoxy matrix/nanoclay reinforced composites under compression cyclic loading were considered. The microscale (lower level) unit cell includes the nanoplatelets reinforcement 
(exfoliated nanoplatelets and intercalated nanoplatelets/cluster) in matrix and/or interfaces. The model is shown schematically in Figure 5. Using the model and the XFEM (eXtended Finite Element Method), the authors simulated the damage evolution in hierarchical composites subject to cyclic compressive loading, considering different structures and distributions of nanoreinforcements. In particular, nanoclay platelets randomly distributed in the matrix and localized in the glass fiber sizing have been considered (as well as different orientations and different degrees of clustering of these platelets). Figure 5 shows the crack paths in the sizing of fibers, reinforced with aligned nanoclay platelets.

Analyzing the effects of the secondary reinforcement on the fatigue resistance of composites, the authors [59] demonstrated that the crack path in the composite with nanomodified interfaces (fiber sizings) is much more rough than in the composite with nanomodified matrix.. In the case of the matrix without nanoreinforcement, the crack grows straightforward, without deviations. The parameter of the crack deviation (Y-coordinate/height of crack peak divided by the $X$-coordinate of the crack peak) is $50 \ldots 85 \%$ higher for the cases when the nanoplatelets are localized in the fiber sizing and not throughout the matrix. This parameter is related with the fracture toughness, and it suggests that the stress of crack initiation becomes much higher for the case of nanostructured fiber/matrix interface.

Further, the fatigue behavior of hierarchical composites with secondary nanoplatelet reinforcement in the polymer matrix, in the fiber/matrix interface and without the secondary reinforcement was compared. Composites with nanoreinforcement achieve the same fatigue life (taken exemplarily at $5.68^{*} 10^{7}$ cycles) as neat composites, but subject to $2 \ldots 3.5$ times higher loadings. Further, composites with the nanoplatelets localized in the fiber/matrix interface layer (fiber sizing) ensure much higher fatigue lifetime than those with the nanoplatelets in the matrix. For instance, for the selected lifetime of $5.68^{*} 10^{7}$ cycles, the applied stress can be $43 \ldots 49 \%$ higher for the composites with the nanoplatelets localized in the fiber/matrix interfaces.

Thus, the nanomodification of weaker phases in the fiber reinforced composites (polymer matrix and fiber/matrix interface layers) ensures the drastic increase in the fatigue lifetime. In particularly, the nanoreinforcements in fiber sizing (fiber/matrix interface) lead to the drastic increase in the fatigue lifetime of the composites.

From the short overview in this section, it can be seen that the interface/interphase regions of polymer composites and nanocomposites influence the strength and mechanical properties of these materials to a large degree. The layers of modified constrained polymer chains formed around nanoparticles due to the nanoparticle/polymer interfacial interaction determine the unusually high strength and mechanical properties of nanocomposites. The nanostructuring of fiber/matrix interfaces in fiber reinforced composites (porosity of fiber sizing/coatings, nanoreinforcement in fiber coatings) allow to control the mechanisms of the composite degradation, increase the lifetime and toughness of the composites.

\section{Nanocrystalline metals: Grain boundaries and their effect on the mechanical properties}


A very promising group of advanced materials for various applications are nanocrystalline metallic materials, e.g. materials with nanosized grains. As demonstrated in a number of works, these materials have better mechanical properties, higher ductility and strength, as compared with usual, coarse grained materials (CGM) [62-64]. One of technologies on nanostructuring of materials is the severe plastic deformation (SPD), which allows to fabricate bulk samples of the materials with the grain sizes 100-500 nm. These materials are called ultrafine grained (UFG) materials. An example of application of such materials is medical and dental implants made from ultrafine grained titanium [60, 61].

Peculiarities of structures of nanocrystalline and ultrafine grained materials as compared with CGMs include the higher fraction of grain boundary (GB) phases, different atomic structure and availability of long-range stresses, enhanced atomic mobility and sometimes segregations in grain boundaries [65], as well as different deformation mechanisms (like grain boundary sliding and diffusion controlled flow).

The concept "grain boundary engineering" for the materials improvement was developed by Watanabe [66]. Observing that an increase in the fraction of the special grain boundaries (i.e., boundaries with low reciprocal number densities of lattice sites) leads to better corrosion, creep and fracture resistance properties of materials, Watanabe suggested to use it to improve the properties of crystalline materials. This approach is especially important for ultrafine grained materials, due to the high fraction of grain boundaries [67].

Characterizing the grain boundary with the use of concident site lattice (CSL) model, considering misorientation of adjoining crystals, one can calculate a relative fraction of grain boundaries with the concident site lattice [68]. It was shown $[69,70]$ that the materials with low relative fraction of grain boundaries which concident site lattice show, among other, high resistance to sliding, fracture and corrosion.

Another approach to the enhancement of mechanical properties of nanocrystalline materials is based on the concept of non-equilibrium grain boundaries $[67,73]$. The grain boundaries which are characterized by higher energies, large amount of dislocations, higher diffusion coefficient, larger free volume in grain boundaries as well as the concentration of alloying elements and formation of their segregations are considered as non-equilibrium grain boundaries in nanocrystalline and ultrafine grained metals.

Frolov et al. [75] also demonstrated in numerical simulations that multiple grain boundary phases with different atomic structures and densities are available in metallic grain boundaries. Reversible first order phase transitions between these phases can take place as a result of injecting point defects or varying temperatures. These interfacial phase transitions, observed in FCC metals, can have a strong effect on the materials properties.

Below, we show several examples on how the structures and defects in grain boundaries of UFG titanium influence the mechanical properties of the material. 


\subsection{Ultrafine grained titanium: Effect of dislocation density and non- equilibrium state of grain boundaries}

The high density of dislocations in grain boundaries of ultrafine grained SPD produced metals is a result of SPD processing, and one of characteristics of non-equilibrium grain boundaries in nanomaterials. As noted in [71], the dislocation density in GBs grows with deformation passes, and is higher in GBs than in grain interior. Generally, the dislocation density in grain boundaries is estimated about 30 times higher after IV deformation stage [72].

In order to analyze effect of non-equilibrium grain boundaries of UFG titanium on its mechanical properties, a series of computational experiments were carried out in [73, 74]. Computational models of UFG titanium were developed in $[73,74]$ on the basis of "composite" representation of nanotitanium, as a hexagon or using Voronoi tessellation with grains surrounded by grain boundary layers (Figure 6). For the description of deformation of grain boundary phase and the grain interior phase, the dislocation density based model was used, which took into account the dislocations immobilization at stored dislocations, storage of a geometrically necessary dislocation density in the interface between boundaries and interiors, mutual annihilation of dislocations of opposite sign, with a proportionality coefficient characterizing the probability of dislocations leaving their slip plane, e.g. by cross slip. For the grain boundaries, an additional term of the second annihilation mechanism is included where two stored dislocations of opposite sign may climb towards each other and annihilate eventually. More details about the materials properties and simulations conditions are given elsewhere $[73,74]$.

In the simulations, it was observed that increasing the dislocation density in grain boundaries of ultrafine grained metals leads to the increased flow stress. This effect is especially strong for the nanoscale grain sizes: the yield stress increases by $18 \%$ in a material with grain size 250 $\mathrm{nm}$, and by $51 \%$ in a material with grain size $50 \mathrm{~nm}$, when initial dislocation density in GBs changes from $1.0 \times 10^{15} / \mathrm{m}^{2}$ to $1.0 \times 10^{18} / \mathrm{m}^{2}$. Apparently, the material with smaller grains is much more sensitive to the dislocation density in grain boundary, and, thus, to the nonequilibrium state of GB than a materials with larger grains. But also the damage value in the materials increases drastically if the initial dislocation density in GB increases [74]: for instance, the simulated highest damage value (under applied strain 0.22 ) increases by $95 \%$ (from 0.22 to 0.43 ) if the initial dislocation density in GB increases from $10^{15}$ to $10^{18}$. Thus, the high dislocation density in GB improves the flow stress, but also creates higher stress gradient and stress triaxiality in triple junction due to big difference in dislocation density and properties in GB and grain interior, and, ultimately, to the higher damage parameter.

From the technology viewpoint, the decrease of grain size and the increase of the initial dislocation density are achieved by increasing the number of passes of the equal-channel angular pressing via the conform scheme (ECAP-C) fabrication technology [76].

\subsection{Precipitates in grain boundaries of UFG metals}

Another physical feature of non-equilibrium state of grain boundaries of ultrafine grained metals is related with the precipitates, segregations and foreign atoms formed in the grain boundaries. Impurity atoms, oxygen and carbon precipitates located in the GBs [77] interact with surrounding atoms of titanium, preventing the dislocation movement in their neighborhood. These 
precipitates, with content of the order of 0.5 at.\% and of atomistic size, are rather spread, and their influence on the mechanical properties is still not well known. Another group of nanoscale secondary phases are dispersoids, e.g., titanium silicides or carbides [78].

Figure 6a shows the computational unit cell models of the ultrafine grained titanium with precipitates in grain boundaries and in grains.

In order to simulate the effect of low content, atomistic size precipitates on the macroscale mechanical properties of $\mathrm{Ti}$, computational models of ultrafine grained titanium with precipitates in grain boundaries and in grains [73, 74] were developed, in which small round foreign inclusions (which might represent physically dispersoids or precipitates or foreign impurity atoms and the regions of their immediate neighborhood with changed properties) are distributed randomly in GBs, grain interior or GB/grain borders. These precipitates are considered as round inclusions, elastic and impenetrable for dislocations.

Figure $6 \mathrm{~b}$ shows the damage (i.e., maximum damage parameter in the model calculated by formulas from [79, 80]) plotted versus the strain curves for the unit cell models for 3 cases: precipitates in GBs, in grain interior and no precipitates. (As shown in [74], the damage formula derived in $[79,80]$ give the most correct damage distribution for nanomaterials). One can see from the curves that the availability of precipitates strongly delays the damage growth: while the damage level 0.2 is achieved in pure UFG titanium at the applied strain $0.1 \ldots 0.13$, the same level of damage is achieved for the materials with precipitates at 0.22 (precipitates in grain interior)...0.35 strains (precipitates in grain boundaries). This means $83 \%$ increase in the critical strains due to the precipitates, and around $300 \%$ increase due to the precipitates located in grain boundaries. Flow stress was the highest for the material with the dispersoids in the grain boundary [74]. For instance, the flow stress at the applied strain 1.0 was $8 \%$ higher (for precipitates in GB) and 5.8\% higher (for precipitates in grain interior), than in UFG Ti without precipitates.

Thus, both the defects (dislocations) and nanoscale structural elements (precipitates, dispersoids) have a strong potential to increase the damage resistance and mechanical properties od advanced nanoscaled materials.

\section{Conclusions}

In this work, we considered several groups of materials, characterized by high strength, and damage resistance. The interface structure versus strength and mechanical properties relationships for these groups of materials have been studied with the use of computational micromechanical models, reflecting the structures and architectures of these materials at several scale levels.

From these studies, one can conclude that the purposeful nanostructuring of interfaces and grain boundaries represents an important reserve of the improvement of the materials properties. Since the material deformation is often localized in and around defects (interfaces and grain boundaries), the structuring of these regions (adding specially arranged and oriented nanoreinforcements, or adding nanoscale defects, changing the local properties) allows to control the deformation and fracture behavior of these weak areas, thus, determining the degradation process in the whole material.

The effect of nanostructured interfaces, phase and grain boundaries (PGB) on the strength 
behavior of the material can be realized by several ways:

- Defects in interfaces and PGB: increasing deformability of interfaces, one can channel the deformation energy from the main, load bearing (fibers in composites) or integrity ensuring (matrix) elements into non-critical areas. The examples of such effects are the microporous interfaces (fiber sizing) in fiber reinforced composites, and, to a some degree, high initial dislocation density in the grain boundaries of ultrafine grained metals.

- Modifying the constitutive behavior of grain boundaries and interfaces: By varying the mechanical behavior of the interfaces and GBs, the load transfer conditions as well deformation behavior can be controlled. The examples of such modifications are the non-equilibrium grain boundaries of ultrafine grained metals and also varied microfibril angles in this layers in wood cells.

- Nanoreinforcing the interfaces and PGBs: while the nanoreinforcement changes the elastic properties of these areas only weakly, it does change the damage mechanisms. It can lead to nanoscale crack bridging, crack deviation and blocking, what drastically changes the crack initiation and crack propagation toughness in the interface region. Thus, while the deformation is still localized in these regions, their damage resistance can be increased. The examples of such effects are the nanoreinforcing platelets in the sizing of fiber reinforced composites, as well as dispersoids and precipitates in the grain boundaries of ultrafine grained metals and mineral bridges in biopolymer layers in nacre.

On the interface structures-properties relationships, one can see from the listed examples that the heterogeneous interfaces have the highest potential as ways to improve the materials properties. Quite often, the interfaces with low stiffness lead to the localization of deformation, while the internal structures of the interfaces (like mineral bridges in nacre, or nanoplatelets in sizing of fiber reinforced composites) allow to control the deformation, damage initiation and fracture processes locally. Such a mechanism can allow to control and increase the material toughness and strength. Another mechanism is related with pre-damaged, porous interfaces, which cause the damage initiation in interfaces, but prevent the crack propagation.

Apparently, the interface reinforcement oriented normally to the main reinforcing elements (like mineral bridges and aragonite platelets, fibrils in S1 and S2 layers of wood, or nanoplatelets aligned normally to fiber axes) ensure the highest toughness and optimal properties.

Further investigations should be directed toward qualitative analysis of the service propertiesinterface structures relationships, and toward the optimal design of interface structures to enhance the strength, toughness and fatigue resistance of materials.

Acknowledgement: The author gratefully acknowledges the financial support of the Danish Council for Strategic Research (DSF) via the Sino-Danish collaborative project "High reliability of large wind turbines via computational micromechanics based enhancement of materials performances" (Ref. no. 10-094539) and the Commission of the European Communities through the 7th Framework Programme Grant VINAT (Contract No. 295322). Furthermore, the author is grateful to the DSF for its support via the Danish Centre for Composite Structures and Materials for Wind Turbines (DCCSM) (Contract no. 09-067212). 


\section{References:}

1. L. Mishnaevsky Jr, Computational Mesomechanics of Composites, John Wiley, 2007, 280 pp

2. J.K. Kim, Y.W.Mai, High strength, high fracture toughness fibre composites with interface controlA review, Composites Science and Technology, Vol. 41, No. 4, 1991, pp. 333-378

3. Interface Design of Polymer Matrix Composites. Proc. 28th Ris $\varnothing$ International Symposium on Materials Science. Eds B. F. Sørensen et al., Risø National Laboratory, Roskilde, Denmark, 2007

4. Controlled Interphases in Composite Materials, Eds. Hatsuo Ishida, Proc. 3rd Int Conference on Composite Interfaces (ICCI-III), 1990 Cleveland, Ohio, USA

5. S. M. Mukhopadhyay, A. K Karumuri, Nanotube attachment for prevention of interfacial delamination J. Phys. D: Appl. Phys. 43 (2010) 365301 (7pp) doi:10.1088/0022-3727/43/36/365301

6. Mukhopadhyay S M, Karumuri A and Barney I T 2009 Hierarchical nanostructures by nanotube grafting on porous cellular surfaces, J. Phys. D: Appl. Phys.42 195503

7. Wiedemann, W. , Sims, L. ,Abdellah, A. , Exner, A.,Meier, R., Musselman, K. P.,MacManus-Driscoll, J. L., Mueller-Buschbaum, P. , Scarpa, G. , Lugli, P. and Schmidt-Mende, L. (2010). Nanostructured interfaces in polymer solar cells. Applied Physics Letters. 96 (26)

8. Gao, Y. , Marconnet, A., Panzer, M., LeBlanc, S., Dogbe, S., Ezzahri, Y., Shakouri, A. and Goodson, K.E., 2010 Nanostructured Interfaces for Thermoelectrics, Journal of Electronic Materials, Vol. 39, pp. 1456-1462.

9. F. W. Zok, C. G. Levi Mechanical properties of porous-matrix ceramic composites, Advanced Engineering Materials, Vol.3, No. 1-2, pages 15-23, 2001

10. A. G. Evans, F. W. Zok, J. B. Davis, The role of interfaces in fiber-reinforced brittle matrix composites,. Compos. Sci. Technol. 42, 3-24.

11. J. B. Davis, J. P. A. Lofvander, and A. G. Evans, Fiber coating concepts for brittle matrix composites, J. Am. Ceram. Soc. 76, [5] 1249 (1993).

12. Ramachamndra Rao P. (2003), Biomimetics, Sadhan,a, 28 (3-4), pp. 657-676.

13. M.A. Meyers, P.-Y. Chen, A.Y.M. Lin, Y.Seki, Biological materials: Structure and mechanical properties, Progress in Materials Science 53 (2008) 1-206

14. H. Ehrlich, H. Worch, Sponges as natural composites: from biomimetic potential to development of new biomaterials, Porifera research: Biodiversity, innovation and sustainability- 2007, pp.303-311

15. G. Mayer, M.Sarikaya, Rigid biological composite materials: Structural examples for biomimetic design Experimental Mechanics, 2002, Volume 42, Issue 4, pp 395-403

16. F. Song and Y.L. Bai, Effects of nanostructures on the fracture strength of the interfaces in nacre, J. Mater. Res., Vol. 18, No. 8, 2003

17. F.Song, A.K. Soh, Y.L. Bai, Structural and mechanical properties of the organic matrix layers of nacre Biomaterials 24 (2003) 3623-3631

18. Schaeffer, T.E.; Ionescu-Zanetti, C.; Proksch, R.; Fritz, M.; Walters, D.A.; Almquist, N.; Zaremba, C.M.; Belcher, A.M.; Smith, B.L.; Stucky, G.D.; Morse, D.E.; Hansma, P.K.: Does Abalone Nacre Form by Heteroepitaxial Nucleation or by Growth through Mineral Bridges? - In: Chem. Mat. 9 (1997) S. 1731-174

19. Smith, B., Schaffer, T., Viani, M., Thompson, J., Frederick, N., Kindt, J., Belcher, A., Stucky, G. Morse, D. and Hansma, P. (1999) Molecular mechanistic origin of the toughness of natural adhesives, fibres and composites. Nature 399, pp. 761-763

20. D. R Katti, S.M.Pradhan, K.S Katti Modeling the organic-inorganic interfacial nanoasperities in a model bio-nanocomposite, nacre. Rev.Adv.Mater.Sci 01/2004; 6:162-168.

21. Qi, H.J., Bruet, B.J.F, Palmer, J. S., Ortiz, C. and Boyce, M.C. (2005) Micromechanics and macromechanics of the tensile deformation of nacre, Mechanics of Biological Tissues, Ed. G. A. Holzapfel, R.W. Ogden, Springer-Verlag, Graz, p. 175-189

22. S. Marshall et al, The dentin-enamel junction - a natural, multilevel interface, J European Ceramic Society, Vol. 23, No. 15, 2003, pp. 2897-2904

23. L. Mishnaevsky Jr, H. Qing, Micromechanical modelling of mechanical behaviour and strength of wood: State-of-the-art review, Computational Materials Science, Vol. 44, No. 2, 2008, pp. 363-370

24. H. Qing, L. Mishnaevsky Jr., 3D multiscale micromechanical model of wood: From annual rings to microfibrils, Int J Solids and Structures, Vol. 47, No. 9, 1 2010, pp. 1253-1267

25. H. Qing, and L. Mishnaevsky Jr, 3D hierarchical computational model of wood as a cellular material with fibril reinforced, heterogeneous multiple layers, Mechanics of Materials, Vol. 41, 9, 2009, pp. 1034-1049

26. Booker, R.E. and Sell, J. (1998). The nanostructure of the cell wall of softwood and its functions in a living tree. Holz als Roh- und Werkstoff, 56: 1-8.

27. Booker, R.E. (1995). The reason for the microfibril orientations in the cell wall of trees. In: Recent Advances in Wood Anatomy. Eds. L.A. Donaldson, A.P. Singh,B.G. Butterfield, J. Whitehouse. NZ Forest Research Institute Ltd. pp. 273-282. 
28. L. Mishnaevsky Jr., P. Brøndsted, R. Nijssen, D. J. Lekou and T. P. Philippidis, Materials of large wind turbine blades: Recent results in testing and modelling, Wind Energy, Vol. 15, No.1, pp, 83-97, 2012

29. L. Mishnaevsky Jr and P. Brøndsted, Micromechanisms of damage in unidirectional fiber reinforced composites: 3D computational analysis, Composites Sci \& Technol, Vol. 69, No.7-8, 2009, pp. 10361044

30. H. Qing, and L. Mishnaevsky Jr, Unidirectional high fiber content composites: Automatic 3D FE model generation and damage simulation, Computational Materials Science, Vol. 47, 2, 2009, pp. 548555

31. L. Mishnaevsky Jr and P. Brøndsted, Three-dimensional numerical modelling of damage initiation in UD fiber-reinforced composites with ductile matrix, Materials Science \&Engineering: A, Vol.498, No. 1-2, 2008, pp. 81-86

32. H. W. Wang, et al, Single fibre and multifibre unit cell analysis of strength and cracking of unidirectional composites, Computational Materials Science, Vol. 46, No. 4, 2009, Pages 810-820

33. O. K. Buryan and V. U. Novikov, Modeling of the interphase of polymer-matrix composites: determination of its structure and mechanical properties, Mechanics of Composite Materials, Vol. 38, No. 3, 2002, 187-190

34. Downing T. D., Kumar R., Cross W. M., Kjerengtroen L. and Kellar J. J. (2000) Determining the interphase thickness and properties in polymer matrix composites using phase imaging atomic force microscopy and nanoindentation, J. Adhesion Science and Technology, Vol. 14, 14, pp. 1801-1812

35. Huang Y, Petermann J (1996). Interface layers of fiber-reinforced composites with transcrystalline morphology. Polymer Bulletin, 36(4), pp.517-524

36. Asp L. E., Berglund L. A. and Talreja R. (1996) Effects of fiber and interphase on matrix-initiated transverse failure in polymer composites Composites Science and Technology Vol. 56, 6, pp. 657-665

37. L.Mishnaevsky Jr, Micromechanical analysis of nanocomposites using 3D voxel based material model, Composites Science \& Technology, 72 (2012) 1167-1177

38. ML Chan et al, Mechanism Of Reinforcement In A Nanoclay/Polymer Composite, Composites Part B: Engineering, Vol. 42, No. 6, 2011, Pp. 1708-1712

39. J.J.Karippal, H. N. Narasimha Murthy, K.S. Rai, M. Sreejith, M. Krishna, Study of mechanical properties of epoxy/glass/nanoclay hybrid composites, J Composite Materials, 22, 2011, doi: $10.1177 / 002199831038908$

40. Odegard GM, Clancy TC, Gates TS. Modeling of the mechanical properties of nanoparticle/polymer composites. Polymer. 2005;46(2):553-562

41. H.W. Wang et al., Nanoreinforced polymer composites: 3D FEM modeling with effective interface concept, Composites Scie \& Technol, Vol. 71, No. 7, 2011, pp- 980-988

42. R.D. Peng et al.. Modeling of nano-reinforced polymer composites: Microstructure effect on the Young's modulus, Computational Materials Science, 60 (2012) 19-31

43. G.M. Dai, L. Mishnaevsky Jr., Damage evolution in nanoclay-reinforced polymers: a threedimensional computational study, Composites Science \& Technology, 74 (2013) 67-77

44. J.J. Luo and I.M. Daniel, Characterization and Modeling of Mechanical Behavior of Polymer/Clay Nanocomposites, Compos Sci Technol 63 (2003), pp. 1607-1616

45. S. Yang and M. Cho, Scale bridging method to characterize mechanical properties of nanoparticle/polymer nanocomposites Appl. Phys. Lett. 93, 043111 (2008); doi:10.1063/1.2965486

46. J.L. Tsai, S. H. Tzeng, Characterizing Mechanical Properties of Particulate Nanocomposites Using Micromechanical Approach.J Composite Materials, Vol. 42, No. 22/2008, p. 2345- 2361

47. Mesbah, A et al (2009), Experimental characterization and modeling stiffness of polymer/clay nanocomposites within a hierarchical multiscale framework, J Applied Polymer Science, 114: 32743291

48. Y.Xu, S. V. Hoa, Mechanical properties of carbon fiber reinforced epoxy/clay nanocomposites, Composites Science and Technology, Vol. 68, 3-4, 2008, pp. 854-861

49. A. Godara et al., Influence of carbon nanotube reinforcement on the processing and the mechanical behaviour of carbon fiber/epoxy composites, Carbon, Vol.47, 12, 2009, pp. 2914-2923

50. J. Zhu et al., Processing a glass fiber reinforced vinyl ester composite with nanotube enhancement of interlaminar shear strength, Compos Sci Technol 67 (7-8) (2007), pp. 1509-1517

51. E. Bekyarova et al., Functionalized single-walled carbon nanotubes for carbon fiber-epoxy composites, J Phys Chem C 111 (2007), pp. 17865-17871

52. E. Bekyarova, E.T. Thostenson, A. Yu, H. Kim, J. Gao and J. Tang et al., Multiscale carbon nanotubecarbon fiber reinforcement for advanced epoxy composites, Langmuir 23 (7) (2007), pp. 3970-3974. E.

53. S.S. Wicks, R.G. de Villoria, B. L. Wardle, Interlaminar and intralaminar reinforcement of composite laminates with aligned carbon nanotubes, Composites Science and Technology, Vol 70, No 1, 2010, pp $20-28$

54. G.Chatzigeorgiou, G. Don Seidel, D. C. LagoudasEffective mechanical properties of "fuzzy fiber" composites, Composites Part B: Engineering, Vol.43, No. 6, 2012, pp. 2577-2593 
55. P.C. Ma, Y.Zhang, Perspectives of carbon nanotubes/polymer nanocomposites for wind blade materials, Renewable and Sustainable Energy Reviews, Vol.30, 2014, pp. 651-660

56. P.C. Ma, J.K. Kim, Carbon nanotubes for polymer Reinforcement. BocaCRC Press, Raton (2011)

57. H. Qian, E.S. Greenhalgh, M.S.P. Shaffer, A. Bismarck, Carbon nanotube-based hierarchical composites: a review, J Mater Chem, 20 (2010), pp. 4751-4762

58. S.U. Khan, J.K. Kim, Impact and delamination failure of multiscale carbon nanotube-fiber reinforced polymer composites: a review, Int J Aeronaut Space Sci, 12 (2011), pp. 115-133

59. G.M. Dai, L. Mishnaevsky Jr, Fatigue of multiscale composites with secondary nanoplatelet reinforcement: 3d computational analysis, Composites Science and Technology Composites Science and Technology, Vol. 91, 2014, pp. 71-81

60. L. Mishnaevsky Jr, E. Levashov, Editorial, Computational Materials Science, 2013, Vol. 76,2013, pp.1-2

61. L. Mishnaevsky Jr., E. Levashov, R. Valiev, E.Rabkin, E. Gutmanas et al. Nanostructured titanium based materials for medical implants: Modeling and development, Materials Science and Engineering R, doi: 10.1016/j.mser.2014.04.002

62. R. Z. Valiev, Nanostructuring of metals by severe plastic deformation for advanced properties, Nature Materials 3, 511 - 516 (2004)

63. R.Z. Valiev, R.K. Islamgaliev, I.V. Alexandrov, Bulk nanostructured materials from severe plastic deformation, , Progress of Material Science. 2000, 45: 103-189

64. Mishnaevsky Jr, L., Levashov E., Editorial Notes, Computational Materials Science, 2013, Vol. 76,2013, pp.1-2

65. X. Sauvage., G. Wilde., S. V. Divinski., et al., Grain boundaries in ultrafine grained materials processed by severe plastic deformation and related phenomena, Materials Science and Engineering: A 2012,540(1):1-12

66. T. Watanabe, An Approach to grain-boundary design for strong and ductile polycrystals, Res Mechanica, v. 11, pp. 47-84, 1984;

67. R. Z. Valiev., I. V. Alexandrov., N. A. Enikeev., et al., Towards enhancement of properties of UFG metals and alloys by grain boundary engineering using SPD processing, Reviews on Advanced Materials Science. 2010, 25: 1-10

68. V.Randle Refined approaches to the use of the coincidence site lattice JOM1998, Volume 50, Issue 2, pp 56-59

69. G. Palumbo et al., Applications for grain-boundary engineered materials, JOM, 50(2), 1998, pp. 40-43

70. G. Palumbo, E. M. Lehockey, P. Lin, U. Erb and K. T. Aust, A grain boundary engineering approach to materials reliability, MRS Proceedings of the Symposium on Interfacial Engineering for Optimized Properties, Vol. 458, (1997) 273-383

71. M. Besterci et al, Formation of ultrafine-grained (UFG) structure and mechanical properties by severe plastic deformation (SPD), Metalurgija 47 (2008) 4, 295-299

72. Y. Estrin., L. Toth., A. Molinari., et al., A dislocation-based model for all hardening stages in large strain deformation, Acta Materialia. 1998,46:5509-5522

73. H.S Liu, W. Pantleon, L.Mishnaevsky Jr, Non-equilibrium grain boundaries in UFG titanium: Computational study of sources of the material strengthening, Computational Materials Science, , 83 (2014) 318-330

74. H.S Liu, L.Mishnaevsky Jr, Gradient ultrafine-grained titanium: computational study of mechanical and damage behavior, Acta materialia, Vol. 71, 2014, pp. 220-233

75. T. Frolov, D. L. Olmsted, M. Asta, Y. Mishin,Structural phase transformations in metallic grain boundaries, Nat. Commun. 4, 1899 (2013).

76. D. V. Gunderov et al, Evolution of microstructure, macrotexture and mechanical properties of commercially pure Ti during ECAP-conform processing and drawing, Materials Science \& Engineering A 562 (2013) 128-136

77. I. Semenova et al., Enhanced strength and ductility of ultrafine-grained Ti processed by severe plastic deformation, Advanced Engineering Materials. Special Issue: Bulk Nanostructured Materials. 2010,12(8): 803-807

78. Handtrack D, Sauer C, Kieback B Microstructure and properties of ultrafine-grained and dispersionstrengthened titanium materials for implants, J Materials Science 43 (2008), 671-679

79. J. Lin, Y.Liu, T.A. Dean, A Review on damage mechanisms, models and calibration methods under various deformation conditions, Int. J Damage Mechanics, 2005 vol. 14 no. 4 299-319

80. Lin, J. , Hayhurst, D.R. and Dyson, B.F. (1993). The standard ridges uniaxial testpiece: computed accuracy of creep strain, J. of Strain Analysis, 28(2): 101-115 


\section{Figures:}

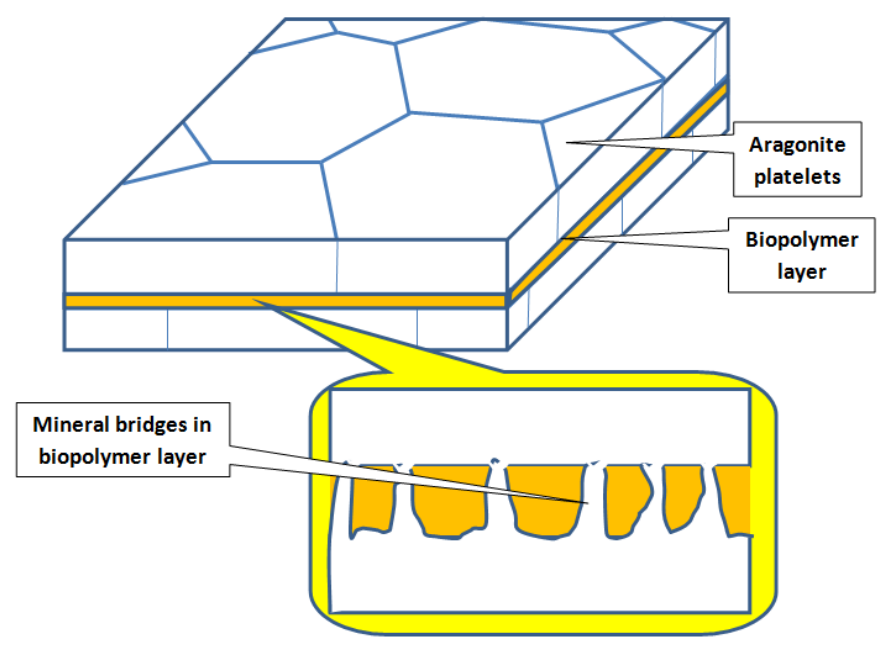

\section{\begin{tabular}{l|ll}
\hline Figure & 1. Schema of microarchitecture of nacre: aragonite platelets, biopolymer layer
\end{tabular}} and mineral bridges (after $[16,17]$ )

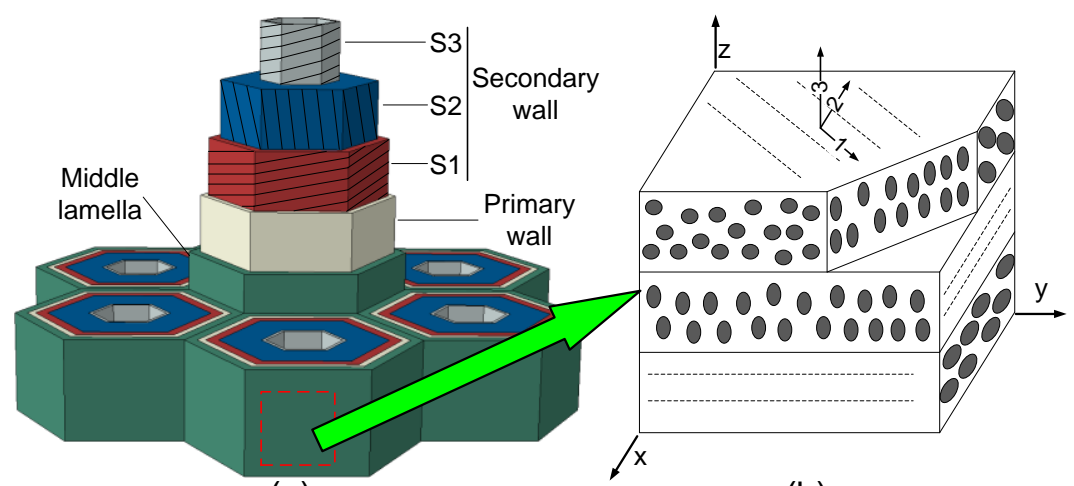

(a)

(b)

\begin{tabular}{|l|l|}
\hline Figure & 2. $\begin{array}{l}\text { Multiscale model of wood as layered, cellular (a) and fibril reinforced (b) } \\
\text { material }[24,25]^{*} \text {. The thin layers S1, S3 with fibrils perpendicular to the fibrils }\end{array}$ \\
\end{tabular}
in thick S2 layer control the buckling and fracture resistance

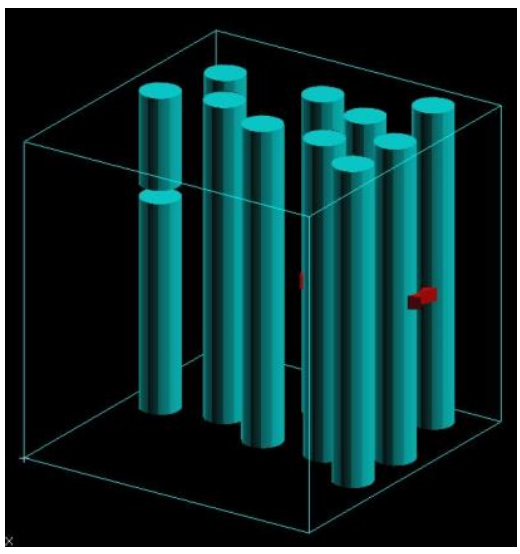

(a)

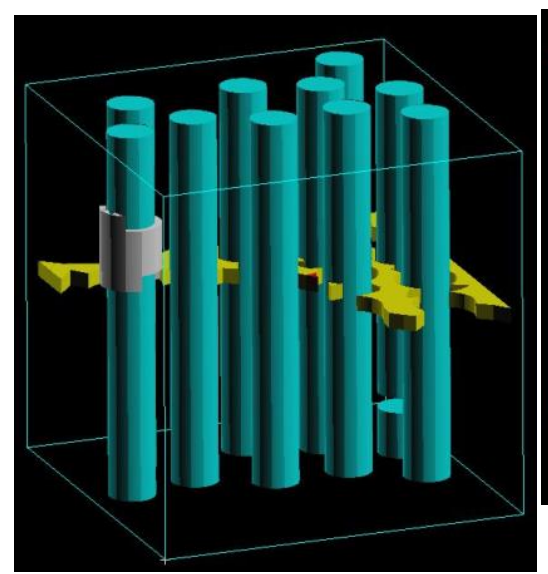

(b)

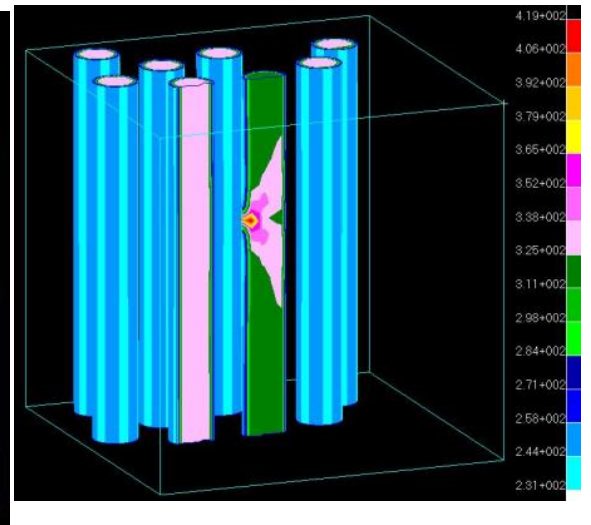

(c)

\footnotetext{
* Reprinted with kind permission from Elsevier
} 


\begin{tabular}{|l|l|}
\hline Figure & 3. $\quad \begin{array}{l}\text { Simulated damage mechanism in fiber reinforced polymer composites: } \\
\text { Competition of damage mechanisms. Reprinted from [29]*. (a and b). Interface } \\
\text { is damaged (red region) in a region far from the first cracked fiber; matrix } \\
\text { crack is formed far from the region with damaged interface. (c) Stress in a fiber } \\
\text { is lower than in other fibers if its sizing is pre-damaged. }\end{array}$ \\
\hline
\end{tabular}

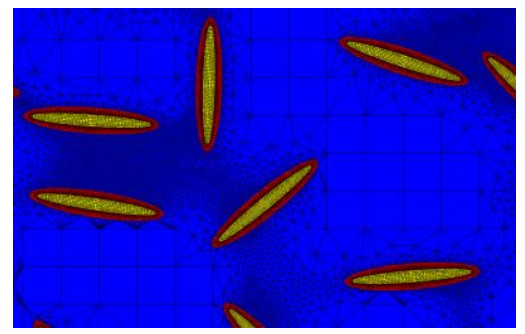

(a)

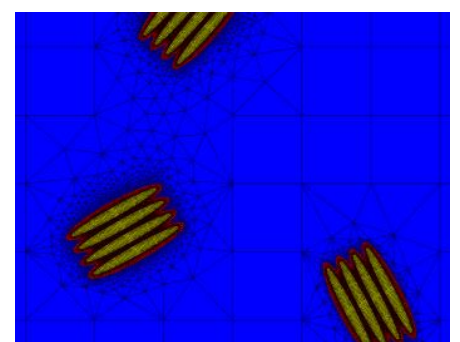

(b)

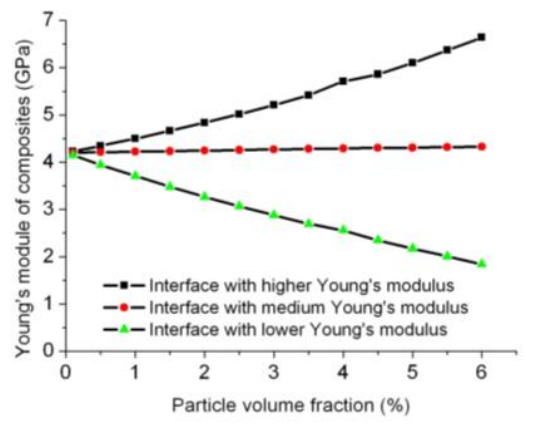

(c)

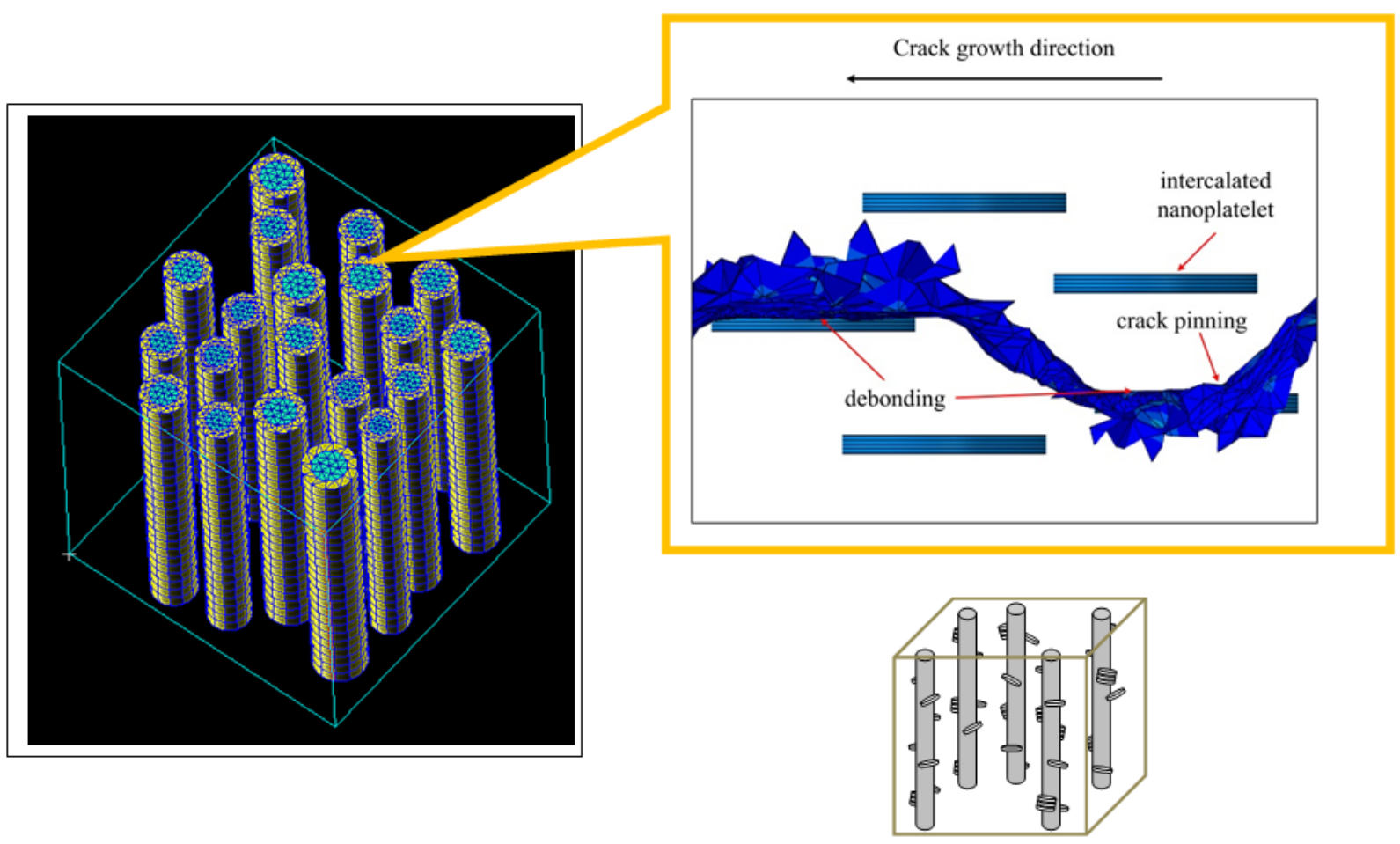

\begin{tabular}{l|ll} 
Figure & $5 . \quad$ Crack propagation in the in the fiber sizing of hierarchical composite (result of
\end{tabular} FE simulations). Right below - schema of hierarchical fiber reinforced composite with secondary nanoplatelet (Reprinted from $[37,59]^{*}$ ) 


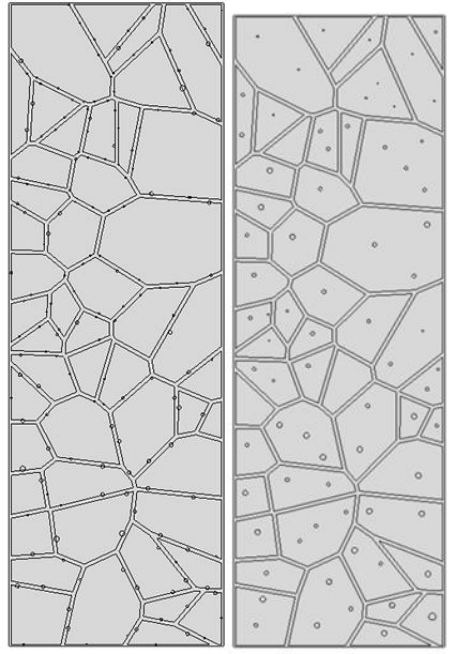

(a)

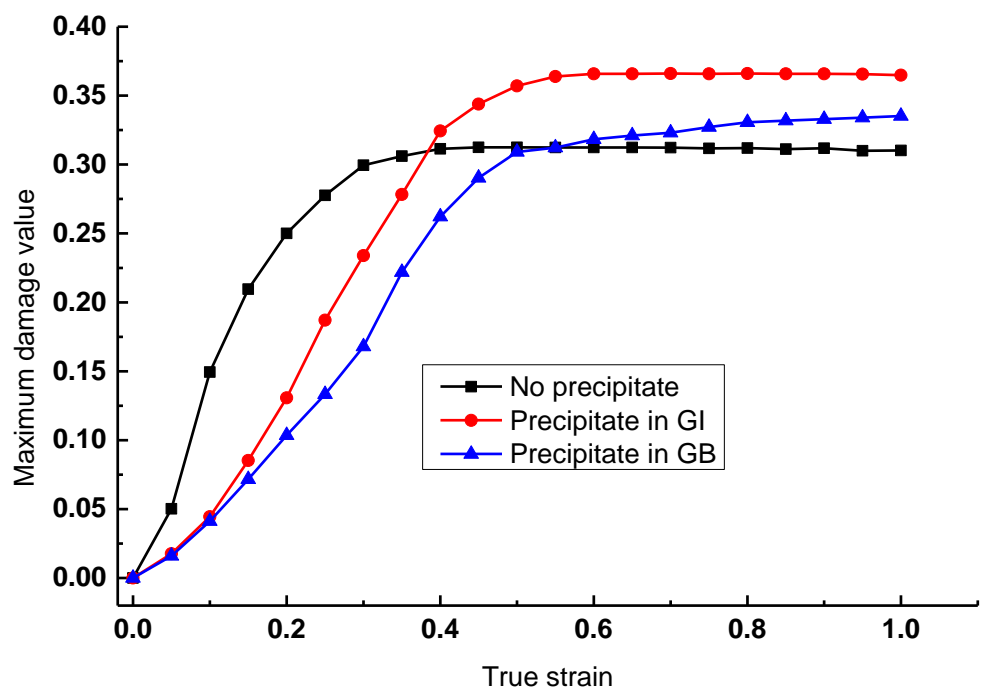

(b)

\begin{tabular}{|l|l|}
\hline Figure & $\begin{array}{l}\text { 6. } \\
\text { Computational model of UFG titanium with precipitates in grain boundary } \\
\text { phase and in grain interior (a) and the effect of the precipitate distribution on } \\
\text { the damage evolution in UFG titanium (b). Reprinted from }[73,74]^{*}\end{array}$ \\
\hline
\end{tabular}

